\title{
Applicability of biobased packaging materials for long shelf-life food products
}

DOI 10.1515/pacres-2016-0002

Received Feb 12, 2016; accepted Jul 22, 2016

\begin{abstract}
The research aim was to evaluate the applicability of biobased plastics for packing long shelf-life food products, both on laboratory and industrial scale. Therefore, the shelf-life (room temperature) of tortilla chips, dry biscuits and potato flakes packed under air or modified atmosphere (MAP) in xylan and cellulose-based packages was evaluated and compared with their shelf-life in reference (conventional) packaging materials. These tests were followed by packaging trials on industrial lines. Furthermore, overall migration studies and printability tests were performed.

Most of the biobased packages showed sufficient barrier towards moisture and gasses to serve as a food packaging material and MAP packaging of long shelf-life food products is possible. But for very moisture-sensitive food products (e.g. dry biscuits), no suited packaging material was found. The quality of the tortilla chips and potato flakes could be guaranteed during their shelf-life, even if packaging materials with lower barrier properties were used. Still, brittleness and seal properties are critical for use on industrial scale (important for use on vertical flow packag-
\end{abstract}

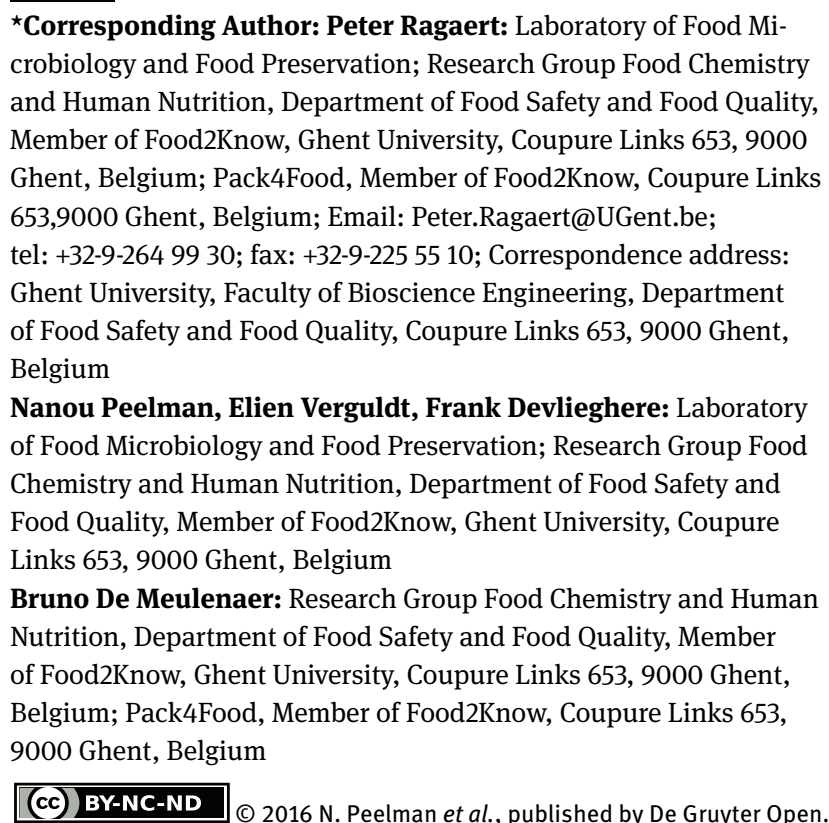
This work is licensed under the Creative Commons Attribution-NonCommercial-NoDerivs 3.0 License. ing machines). Furthermore, the films were printable and migration tests showed compliance with legislation. This study shows promising results towards the industrial application of biobased packaging materials for long shelflife food products.

Keywords: Barrier properties; Bioplastics; Case Studies; Industrial applicability; Shelf-life tests

\section{Introduction}

Until now petrochemical-based polymers such as polypropylene (PP), polyethylene (PE), polyamide (PA) and polyethylene terephtalate (PET) have been intensively used as food packaging materials, because they possess several desired properties, like good mechanical performance and good barrier functions at relatively low cost. However, their intensive use in the food industry has raised questions on their environmental impact leading to an increased interest from the industry in the development of alternative packaging concepts. One of these new concepts is the use of renewable resources instead of crude oil for the production of food packaging materials. But, like conventional packaging, biobased and/or biodegradable packaging must serve a number of important functions, including containment and protection of food, maintaining its sensory quality and safety, and communicating information to consumers [1-3].

A small number of biobased materials can be or are already used nowadays to pack long shelf-life food products, mostly if they do not require high gas and/or water vapor barrier. PLA-based packaging is already used for pasta and fresh produce $[4,5]$. Starch-based packaging is already used for milk chocolates [5]. Cellulose-based packaging is already used for potato chips, organic pasta, organic cereals, nuts, bread, herbs and spices and sweets [4]. Research in the field of biobased plastics is increasing, but the findings of most of these studies do not reach the companies or they are too narrow or too fundamental for immediate implementation. This manuscript contributes in decreasing the knowledge gap concerning biobased plastics among 
the different stakeholders within the food packaging industry and translates technical specifications of biobased plastics into practical information as needed by the industry. This has already been done in the case of short and medium shelf-life food products, as described by Peelman et al. [6], which showed that biobased (multilayer) materials can guarantee the quality of both short and medium shelf-life food products including products packed under modified atmosphere packaging (MAP). However, since long shelf-life food products are packed and stored mostly at room temperature and in some cases under modified atmosphere, the gas barrier requirements are even higher compared to short and medium shelf-life food products. Furthermore, water barrier is also a very important parameter as crisp food products need to maintain their texture during several months. Therefore, increased knowledge is needed on how biobased (multilayer) materials perform when used for long shelf-life food products requiring high gas and/or moisture barrier.

In this paper five commercially available cellulosebased films (Natureflex ${ }^{\mathrm{TM}}$ N913, N931, N948 and NK and Cellophane $\mathrm{T}^{\mathrm{TM}} / \mathrm{M} / \mathrm{PLA}$ ) and one xylan-based film (Skalax, coated on paper) were tested for their applicability as a packaging material (under the form of pouches) for different food products (potato flakes, tortilla chips and dry biscuits). This was done by performing storage experiments with these food products, packed both in the reference (conventional) packaging and in the biobased packaging, this both on lab-scale and industrial scale. Different chemical analyses have been performed throughout storage to monitor the quality of the food products and to compare the performance of the biobased packaging with the reference packaging. In addition, printability tests were performed in order to evaluate the quality of print on different types of biobased packaging. Finally, since packaging materials cannot be used as a food packaging material if they do not comply with legislation, overall migration studies were performed to study the migration behaviour of possible present low molecular components in the biobased packaging. Overall migration studies (in 10 and 95\% ethanol) were performed on five cellulose-based films (Natureflex ${ }^{\mathrm{TM}} \mathrm{N} 913, \mathrm{~N} 931$ and NK, Natureflex ${ }^{\mathrm{TM}} \mathrm{N} 913 /$ PLA and Cellophane $\left.\mathrm{T}^{\mathrm{TM}} / \mathrm{M} / \mathrm{PLA}\right)$, a printed and non-printed multilayer PLA-film and a PLA tray. Currently only scarce information can be found in the scientific literature on the migration behavior of biobased films.

\section{Materials and methods}

\subsection{Chemicals and materials}

Thiobarbituric acid (TBA), propyl gallate and 1,1,3,3tetraethoxypropane (TEP) were purchased from SigmaAldrich (St. Louis, MO, USA). Dichloromethane, $\mathrm{NaCl}$, $\mathrm{HCl}(25 \%)$, pentane $(97 \%), \mathrm{KOH}$, chloroform, potassium iodide, soluble starch, diethylether, $\mathrm{KH}_{2} \mathrm{PO}_{4}$, ethylenediaminetetraacetic acid (EDTA), Na-acetate. $3 \mathrm{H}_{2} \mathrm{O}$ and glacial acetic acid of analytical grade were purchased from Chem-Lab (Zedelgem, Belgium). Trichloroacetic acid (TCA), 4-methyl-2-pentanone spectrophotometric grade (99,5\%), hexanal (96\%) and $n$-heptane (>99\%) were purchased from Acros Organics (Geel, Belgium). $\mathrm{H}_{2} \mathrm{SO}_{4}$ (> $95 \%, \mathrm{~d}=1,83 \mathrm{~g} / \mathrm{ml}$ ), acetonitrile HPLC grade, methanol HPLC grade and methanol analytic grade were provided by Fisher Scientific (Leicestershire, U.K.). Ethanol was purchased from Tailor Made Chemicals (Rekkem-Menen, Belgium). Phenolpthalein indicator was provided by $3 \mathrm{~F}$ Chimica (Sandrigo, Italy). $\mathrm{NaOH}$ (titrisol), Boron-trifluoridemethanol complex and $\mathrm{Na}_{2} \mathrm{~S}_{2} \mathrm{O}_{3}$ (titrisol) was purchased from Merck KGaA (Darmstadt, Germany). Triheptadecanoin (> 99\%) was purchased from Nu-check-prep INC. (Elysian, USA).

\subsection{Food Products}

The tested food products were supplied by different food producers and are shown in Table 1, together with their reference packaging material, the tested biobased packaging material(s), the shelf-life of the food product, the atmosphere conditions (air or MAP) and the analyses that were performed during the storage tests.

As a reference, the shelf-life of each food product packed in their current packaging material was also monitored. The amount of food product that was packed in the biobased package was calculated depending on the dimensions of the reference pouches and on the gas/product ratio in the reference package. For tortilla chips, the biobased packages had the same dimensions $(170.290 \mathrm{~mm})$ and the same food product content (125 g) as the reference package. For the potato flakes, pouches of $170.180 \mathrm{~mm}$ of both the reference films as the biobased films were filled with $100 \mathrm{~g}$ food product. For the dry biscuits, the dimensions and content (1 biscuit) of the reference and biobased packaging was the same.

The nutritional values, $\mathrm{pH}$ and $\mathrm{a}_{w}$ of the food products as being provided by the respective companies are shown 
Table 1: Overview of the reference packaging materials, tested biobased packaging materials, shelf-life, atmosphere conditions and performed analyses on the tested food products.

\begin{tabular}{|c|c|c|c|c|c|}
\hline $\begin{array}{l}\text { Food } \\
\text { Product }\end{array}$ & Reference Packaging ${ }^{b}$ & Biobased packaging $^{b}$ & Shelf-life & $\begin{array}{l}\text { Packaging } \\
\text { conditions }\end{array}$ & Analyses $^{c}$ \\
\hline $\begin{array}{l}\text { Potato } \\
\text { flakes }\end{array}$ & PETmet/glue/PE & $\begin{array}{c}\text { Skalax } \\
\text { (paper/xylan/PE) } \\
\text { Natureflex }{ }^{T M} \text { N931 }\end{array}$ & $\begin{array}{c}18 \\
\text { months }\end{array}$ & $100 \% \mathrm{~N}_{2}$ & $\begin{array}{c}\text { Gas, } \mathrm{pH}, \mathrm{a}_{w}, \\
\text { MDA, hexanal, } \\
\text { organoleptic }\end{array}$ \\
\hline $\begin{array}{l}\text { Tortilla } \\
\text { chips }\end{array}$ & $\mathrm{PP} / \mathrm{PP}$ & $\begin{array}{c}\text { Cellophane }{ }^{T M} / M / P L A \\
\text { Natureflex }{ }^{T M} \text { N913 } \\
\text { Natureflex }{ }^{T M} \text { N931 }\end{array}$ & 6 months & Air & $\begin{array}{l}\mathrm{pH}, \mathrm{a}_{w}, \mathrm{MDA}, \mathrm{PO}, \\
\mathrm{FFA} \text {, organoleptic }\end{array}$ \\
\hline $\begin{array}{c}\text { Dry } \\
\text { biscuits }^{a}\end{array}$ & $\begin{array}{c}\text { Individual: acrylic } \\
\text { coating/OPP/PVdC } \\
\text { Bundle: heat sealable } \\
\text { skin/OPP/heat sealable } \\
\text { skin }\end{array}$ & $\begin{array}{c}\text { Cellophane } e^{T M} M / P L A \\
\text { Natureflex }{ }^{T M} N 948 \\
\text { Natureflex }{ }^{T M} N K\end{array}$ & 30 weeks & Air & $a_{w}$, organoleptic \\
\hline
\end{tabular}

${ }^{a}$ Individual packages of dry biscuits packed in the reference and in the biobased materials were packed in a conventional bundle pack

${ }^{b}$ PETmet:metallized Polyethylene terephthalate, PE: polyethylene, (O)PP: (Oriented) polypropylene, PVdC: polyvinylidene chloride, PLA: poly lactic acid, M: metallized

${ }^{c} \mathrm{a}_{w}$ : water activity, MDA: malondialdehyde content, PO: peroxide value, FFA: free fatty acid content

in Table 2. The $\mathrm{a}_{w}$-values of these food products indicate that these products are susceptible towards moisture uptake and this moisture uptake can quickly lead to deterioration of the product (e.g. loss of crispness).

\subsection{Packaging}

\subsubsection{Packaging materials}

The packaging materials for the storage tests, printability tests and migration tests were supplied by different companies. The reference packaging materials were provided by the respective food companies. An overview of the materials, their $\mathrm{O}_{2}$ (OTR) and $\mathrm{H}_{2} \mathrm{O}$ (WVTR) transfer rates, their thickness and the supplier is shown in Table 3.

\subsubsection{Pouch packaging}

Pouches of the Natureflex ${ }^{\mathrm{TM}} \mathrm{N} 913$, Natureflex ${ }^{\mathrm{TM}} \mathrm{N} 931$ and Cellophane $^{\mathrm{TM}} / \mathrm{M} / \mathrm{PLA}$ films and the reference films of potato flakes were industrially made by Bastin and Segers \& Balcaen. Pouches of the Skalax film were made at Ghent University (Hand Sealer HZ 300, Willi Kopp e.K. Verpackungssysteme, Reichenbach/Fils, Germany). The pouches were packed under air or under modified atmosphere using a gas packaging unit consisting of a gas mixer (WITT MG18-3MSO, Gasetechnik, Germany) and a gas packaging chamber machine (Multivac A300/42, Sepp. Hagenmüller
KG, Wolfertschwenden, Germany). The nitrogen was delivered by Air Products (Brussels, Belgium). Reference samples for potato flakes were packed at Ghent University. Reference samples for tortilla chips were packed at the respective company. For tortilla chips, after a first test (test 1) with two biobased films (Natureflex ${ }^{\mathrm{TM}} \mathrm{N} 913$ and N931) and the reference film, a second test (test 2) was performed with another biobased film (Cellophane ${ }^{\mathrm{TM}} / \mathrm{M} / \mathrm{PLA}$ ) and the reference film. For the dry biscuits, all packaging was performed at the company (biobased and reference), since no empty pouches with the correct dimensions could be industrially made. For dry biscuits, two packaging concepts were considered. At the company tests were performed with on the one hand individual packed biscuits, both in biobased packaging and reference packaging. On the other hand, tests were also performed with individual packed biscuits packed in a bundle pack (conventional, extra barrier). At Ghent University, no tests were performed with the individual packed biscuits (without a bundle pack).

\subsubsection{Storage and sampling}

All packaged food products were stored at room temperature in cardboard boxes. At analysis date, three packages per package material were sampled for analysis. Leak packages (if MAP packed) were not analyzed. After packaging, a certain amount of samples was returned to and stored at the respective companies for sensorial evaluation 
Table 2: Nutritional value, $\mathrm{pH}$ and $\mathrm{a}_{w}$ of the tested food product.

\begin{tabular}{cccccc}
\hline $\begin{array}{c}\text { Food } \\
\text { Product }\end{array}$ & $\begin{array}{c}\text { Carbohydrates } \\
(\mathbf{g} / \mathbf{1 0 0 g})\end{array}$ & Fat (g/100g) & Protein (g/100g) & $\mathbf{a}_{w}$ & $\mathbf{p H}$ \\
\hline $\begin{array}{c}\text { Potato } \\
\text { flakes }\end{array}$ & 73.0 & $\begin{array}{c}1.0(0.8 \\
\text { saturated) }\end{array}$ & 8.0 & 0.32 & 5.9 \\
$\begin{array}{c}\text { Tortilla } \\
\text { chips } \\
\begin{array}{c}\text { Dry } \\
\text { biscuits }\end{array}\end{array}$ & 53.3 & $\begin{array}{c}\text { saturated) } \\
18.7(9.3\end{array}$ & 6.7 & 0.14 & 6.0 \\
\hline
\end{tabular}

Table 3: Oxygen transmission rate (OTR), water vapour transmission rate (WVTR), thickness and supplier of different (biobased) materials [18].

\begin{tabular}{|c|c|c|c|c|c|}
\hline Material $^{\mathbf{a}}$ & Name $^{\mathrm{a}}$ & $\operatorname{TR}\left(c c / m^{2} \cdot d\right)^{b}$ & WVTR(g/m $\left.m^{2} \cdot d\right)^{c}$ & Thickness $\mu \mathrm{m}$ & Supplier \\
\hline \multicolumn{6}{|c|}{ Biobased packaging material } \\
\hline Cellulose/starch & Natureflex ${ }^{\mathrm{TM}} \mathrm{N} 913$ & 9.9 & 10.1 & 55 & $\begin{array}{c}\text { Bastin }^{f} / \\
\text { Be_Natural }^{g}\end{array}$ \\
\hline Metallized cellulose/starch & Natureflex ${ }^{T M}$ N931 & 3.4 & 5.0 & 44 & Be_Natural \\
\hline Cellulose/starch & Natureflex ${ }^{T M}$ N948 & $1^{e}$ & $\rho^{e}$ & 55 & Be_Natural \\
\hline Cellulose & Natureflex ${ }^{T M}$ NK & $5.0^{d}$ & 14.0 & 30 & Be_Natural \\
\hline Cellulose/metal/PLA & Cellophane $^{\mathrm{TM}} / \mathrm{M} / \mathrm{PLA}$ & 9.1 & 9.7 & 46 & Be_Natural \\
\hline $\begin{array}{c}\text { Xylan based coating on } \\
\text { paper }\end{array}$ & Skalax & 3.7 & 24.3 & 9 (xylan) + 91 & Xylophane ${ }^{h}$ \\
\hline multilayer PLA & Bioska 504 & 617.6 & 275.1 & 34 & Be_Natural \\
\hline Cellulose/PLA & Natureflex ${ }^{T M}$ NK/PLA & 11.01 & 11.3 & 60 & $\begin{array}{l}\text { Segers\& } \\
\text { Balcaen }^{i}\end{array}$ \\
\hline PLA tray & - & 46.8 & 3.8 & $200-300$ & HoGent ${ }^{j}$ \\
\hline \multicolumn{6}{|c|}{ Reference packaging material } \\
\hline $\begin{array}{l}\text { PETmet/glue/PE (potato } \\
\text { flakes) }\end{array}$ & / & $<1^{d}$ & $<1$ & / & / \\
\hline PP/PP (tortilla chips) & l & I & 6 & l & l \\
\hline $\begin{array}{l}\text { acrylic coating/OPP/PVdC } \\
\text { (dry biscuits) }\end{array}$ & / & 20 & 4.2 & / & l \\
\hline \multirow{2}{*}{\multicolumn{6}{|c|}{ aETmet: metallized Polyethylene terephthalate, PE: Polyethylene, (0)PP: (Oriented) Polypropylene, PVdC: Polyvinylidene chloride, PLA: Poly }} \\
\hline & & & & & \\
\hline \multicolumn{6}{|l|}{${ }^{b} 23^{\circ} \mathrm{C}-75 \% \mathrm{RH}$} \\
\hline \multicolumn{6}{|l|}{${ }^{c} 38^{\circ} \mathrm{C}-90 \% \mathrm{RH}$} \\
\hline \multicolumn{6}{|l|}{$d_{23}{ }^{\circ} \mathrm{C}-50 \% \mathrm{RH}$} \\
\hline \multicolumn{6}{|c|}{${ }^{e}$ No technical data sheet, but similar to Natureflex ${ }^{\mathrm{TM}}{ }_{\mathrm{N}} 913$ (home compostable version) } \\
\hline \multicolumn{6}{|c|}{$f$ Wetteren, Belgium } \\
\hline \multicolumn{6}{|l|}{${ }^{g}$ Schoten, Belgium } \\
\hline \multicolumn{6}{|l|}{${ }^{h}$ Bohus, Sweden } \\
\hline${ }^{i}$ Liedekerke, Belgium & & & & & \\
\hline$j_{\text {Ghent, Belgium }}$ & & & & & \\
\hline
\end{tabular}


or they were stored at Ghent University and picked up by the company a day before the sensorial evaluation was performed.

\subsection{Analysis}

\subsubsection{Gas measurements}

The gas in the headspace of the package $\left(\mathrm{O}_{2}\right.$ and $\left.\mathrm{CO}_{2}\right)$ was measured in three different packages of the same material by taking a gas sample from the headspace (Checkmate 9900, PBI Dansensor, Ringsted, Denmark).

\subsubsection{Chemical parameters}

\section{$\mathrm{pH}$ and water activity}

The $\mathrm{pH}$, after homogenization ( $3 \mathrm{~g}$ of sample $+12 \mathrm{~g}$ of water), and water activity $\left(\mathrm{a}_{w}\right)$ of three samples packed in the same packaging material were measured $(\mathrm{pH}$ meter, SevenEasy Mettler Toledo, Zaventem, Belgium/ $\mathrm{a}_{w}$-Kryometer, Nagy, Gaeufelden, Germany).

\section{Fat Extraction}

The fat was extracted out of 30-50 g of sample according to the method described by Papastergiadis et al. [7], which was a modified Blight and Dyer method. The fat was used to determine the peroxide value and the free fatty acid content of three different samples packed in the same material.

\section{Lipid rancidity parameters}

The peroxide value (primary oxidation product; $\mathrm{PO}$-value) was determined according to the iodometric method of Lea and Wheeler $[8,9]$. The free fatty acid content (measure of hydrolytic rancidity) was determined titrimetrically using $\mathrm{NaOH}(0,1 \mathrm{~N})$ by adding 50-ml solvent mixture (1:1 diethylether + ethanol) and some drops of phenolphthalein (10 g/l in 95\% alcohol solution) to the extracted fat (2-3 g). Malondialdehyde (MDA) (degradation product of polyunsaturated fatty acids) was extracted out of $\pm 10 \mathrm{~g}$ of sample and HPLC analyzed. Both extraction and HPLC determination of the extract were carried out according to the methods described by Papastergiadis et al. [7]. To determine the hexanal content (secondary oxidation product), 5-ml of water was added to $0.5 \mathrm{~g}$ of sample. Standard addition with hexanal and 4-methyl-2-pentanone, as an internal standard, was performed before the vials were analysed. Chromatographic analysis was performed in an $\mathrm{Ag}$ ilent 7890A GC equipped with a 5975C Mass Spectrometer (Agilent Technologies, Palo Alto, CA). The sample $(18 \mu \mathrm{ml})$ was introduced into the injector operating in the splitless mode at $40^{\circ} \mathrm{C}$ and the separation was carried out in an Agilent DB-624 $60 \mathrm{~m} ; 0,25 \mathrm{~mm} ; 1,4 \mu \mathrm{mm}$ capillary column. The carrier gas was helium at a constant flow of $1,3 \mathrm{ml} / \mathrm{min}$ and the oven temperature was programmed from $38^{\circ} \mathrm{C}$ (held for $2 \mathrm{~min}$ ) to $115^{\circ} \mathrm{C}$ at a rate of $4^{\circ} \mathrm{C} / \mathrm{min}$ and from $115^{\circ} \mathrm{C}$ to $240^{\circ} \mathrm{C}$ at a rate of $15^{\circ} \mathrm{C} / \mathrm{min}$.

\subsubsection{Sensory evaluation}

A sensory evaluation was performed for each food product at the respective food company to determine the influence of the different packaging materials on some organoleptic parameters. Even though in this way, not all the evaluations were performed using the same method, it was preferred to let the respective companies carry out the sensorial tests themselves, because it is believed that they know the sensorial properties of their own product best and they can make a reliable judgment.

For potato flakes, the sensory evaluation consisted of the reconstitution (by the addition of water) of the mashed potatoes (only after month one), indicated by OK or not OK, possibly supplemented by other observations. This test was performed by a company expert. The sensory evaluation for tortilla chips was also performed by a company expert. The moisture content was determined (by a halogen moisture meter, $125^{\circ} \mathrm{C}, 4.5 \mathrm{~g}$ sample) and the flavor was judged. For dry biscuits, the moisture uptake of the individual packed dry biscuits with and without a conventional bundle pack was measured and the crispness was evaluated by a company expert.

\subsubsection{Performance in industrial environment}

The introduction of good functional biobased materials as a packaging material on industrial scale can only be successful if these materials can be handled on industrial packaging machines. Therefore, several films (Natureflex ${ }^{\mathrm{TM}}$ N913, N931, N948 and NK, Cellophane $^{\mathrm{TM}} / \mathrm{M} /$ PLA, Natureflex ${ }^{\mathrm{TM}}$ NK/PLA and Skalax) were selected to be tested on industrial packaging lines (vertical and horizontal flow pack machines) at different food companies. The seal properties and the speed of 
the machine were altered to make good sealed packages. The ability to make good sealed packages is very important when long shelf-life food products are packed, since leaks in the package can counteract the carefully selected moisture and/or gas barrier properties of the film. These tests were performed for potato flakes and dry biscuits. In case good sealed packages could be made, gas analyses (potato flakes) on these packages were performed during the shelf-life.

\subsubsection{Printability tests}

Since industrially used food packaging films are usually printed, the printability of a packaging film is an important aspect to take into account when it comes to commercializing a new film. Therefore, two films were selected to be printed: Natureflex ${ }^{\mathrm{TM}} \mathrm{N} 913$ and a multilayer PLA film. The Natureflex ${ }^{\mathrm{TM}} \mathrm{N} 913$ film was printed in the context of a collaboration between two companies involved in the project (Be_Natural and Lima (Aalter, Belgium)). The multilayer PLA film was printed in two different colors (cyan and magenta, two full surfaces, partly overlapping) at low temperature $\left(55^{\circ} \mathrm{C}\right)$ at Vitra NV (Schoten, Belgium). The print test was performed twice, with a different volume $\left(\mathrm{cm}^{3} / \mathrm{m}^{2}\right)$ of cyan.

After printing, a scratch test (scratching over the surface with a fingernail and visual inspection), tape test (applying tape onto the surface and pulling it off to see if the ink comes off) and residual solvent content analysis (GC, Clarus ${ }^{\circledR} 600$ ) were performed at the printing company and a tensile test (the film is stretched after which the adhesion of the ink onto the film is visually checked), tape test (see before) and dry weight determination were performed at the Flemish Plastic Centre (VKC) (Kortrijk, Belgium).

\subsubsection{Migration tests}

Since packaging films cannot be used as a food packaging material if they do not comply with legislation, overall migration studies were performed to test the migration behavior of present low molecular components in the films. Migration tests were performed in simulant A $(10 \%$ ethanol) and simulant D2 (vegetable oil or alternative) for 10 days at $\pm 40^{\circ} \mathrm{C}$. These simulants were selected, since according to Commission Regulation (EU) No 10/2011 [10], compliance with the overall migration limit for all types of food (except acidic food products), can be demonstrated by testing in these two simulants. The test condition (10 days at $40^{\circ} \mathrm{C}$ ) was selected, since according to Commis- sion Regulation (EU) No 10/2011 [10], this condition (mentioned as test number OM 2 in this legislation) is valid for any long term storage at room temperature or below. The overall migration was tested for the Natureflex ${ }^{\mathrm{TM}} \mathrm{N} 913$ and $\mathrm{N} 931$ films, for the Natureflex ${ }^{\mathrm{TM}} / \mathrm{PLA}$ film, for the Cellophane $\mathrm{TM}^{\mathrm{TM}} / \mathrm{M} / \mathrm{PLA}$ film, for the Natureflex ${ }^{\mathrm{TM}} \mathrm{NK}$ film, for the printed and non-printed multilayer PLA film and for a PLA tray.

Overall migration tests in vegetable oil (olive oil) were performed by making use of migration cells. Films $\left(1.4 \mathrm{dm}^{2}\right)$ were conditioned at 50\% RH $\left(178 \mathrm{ml} \mathrm{H}_{2} \mathrm{SO}_{4} / \mathrm{l}\right)$ in a dessicator and weighted every $24 \pm 4$ hours. If the difference in mass between two time intervals was less than $5 \mathrm{mg}$, the starting mass of the sample could be determined. The sample was then placed in a stainless steel migration cell, filled with olive oil (Bertolli dal 1865 classico, Bertolli, Tavarnella val di pesa, Italy) and stored during 10 days as $40^{\circ} \mathrm{C}$. Two blank samples (films not in contact with olive oil) were also tested. After 10 days, the olive oil was removed and the samples conditioned, first at $80 \% \mathrm{RH}$ $\left(102 \mathrm{ml} \mathrm{H}_{2} \mathrm{SO}_{4} / \mathrm{l}\right)$ for $24 \pm 4$ hours and then at $50 \% \mathrm{RH}$ and weighted every $24 \pm 4$ hours. The end mass of the sample could be determined in the same way as the start mass. The absorbed oil was extracted from the film with pentane. The pentane was then evaporated and the oil esterified by refluxing for $10 \mathrm{~min}$ after addition of $10 \mathrm{ml}$-heptane and $10 \mathrm{ml} \mathrm{KOH} \mathrm{(10} \mathrm{ml} \mathrm{KOH}$ in $11 \mathrm{MeOH})$ and refluxing for $2 \mathrm{~min}$ after addition of $5 \mathrm{ml}$ boron-trifluoride-methanol complex (Merck). After addition of saturated NaCl-solution (40 g $\mathrm{NaCl}$ in $100 \mathrm{ml}$ distilled water), a clear upper phase was obtained. This upper phase was pipetted in a test tube and subsequently in a GC-vial. Chromatographic analysis was performed in Varian CP-3380 (Varian Analytical Instruments, Mitchel Drive, USA). The sample $(1 \mu \mathrm{ml})$ was introduced into the injector operating $320^{\circ} \mathrm{C}$ and the separation was carried out in an Varian CP-Sil 8 CB $30 \mathrm{~m}, 0.32 \mathrm{~mm}$, $0.25 \mu \mathrm{mm}$ capillary column. The oven temperature was programmed from $100^{\circ} \mathrm{C}$ (held for $2 \mathrm{~min}$ ) to $290^{\circ} \mathrm{C}$ at a rate of $15^{\circ} \mathrm{C} / \mathrm{min}(10 \mathrm{~min})$. Triheptadecanoin $(20.35 \mathrm{mg} / 10 \mathrm{ml}$ heptane) was used as an internal standard and a calibration curve was made (50 $\mu \mathrm{mg}$ olive oil $/ \mathrm{ml} \mathrm{n}$-heptane).

Alternatively, 95\% ethanol was also used as a simulant for fatty foods. For the overall migration in both $10 \%$ and 95\% ethanol the method of total immersion was used. The multilayer bioplastics were cut $\left(1 \mathrm{dm}^{2}\right)$, after which they were immersed in $200 \mathrm{ml} \mathrm{10 \%}$ or $95 \%$ ethanol $(10 \mathrm{ml}$ or $95 \mathrm{ml}$ ethanol in respectively $90 \mathrm{ml}$ or $5 \mathrm{ml}$ distilled water) and stored for 10 days at $40^{\circ} \mathrm{C}$. Two blank samples (food simulant without a film) were also tested. After 10 days the films were removed and the ethanol was evaporated by the following method: little aluminum or stone 


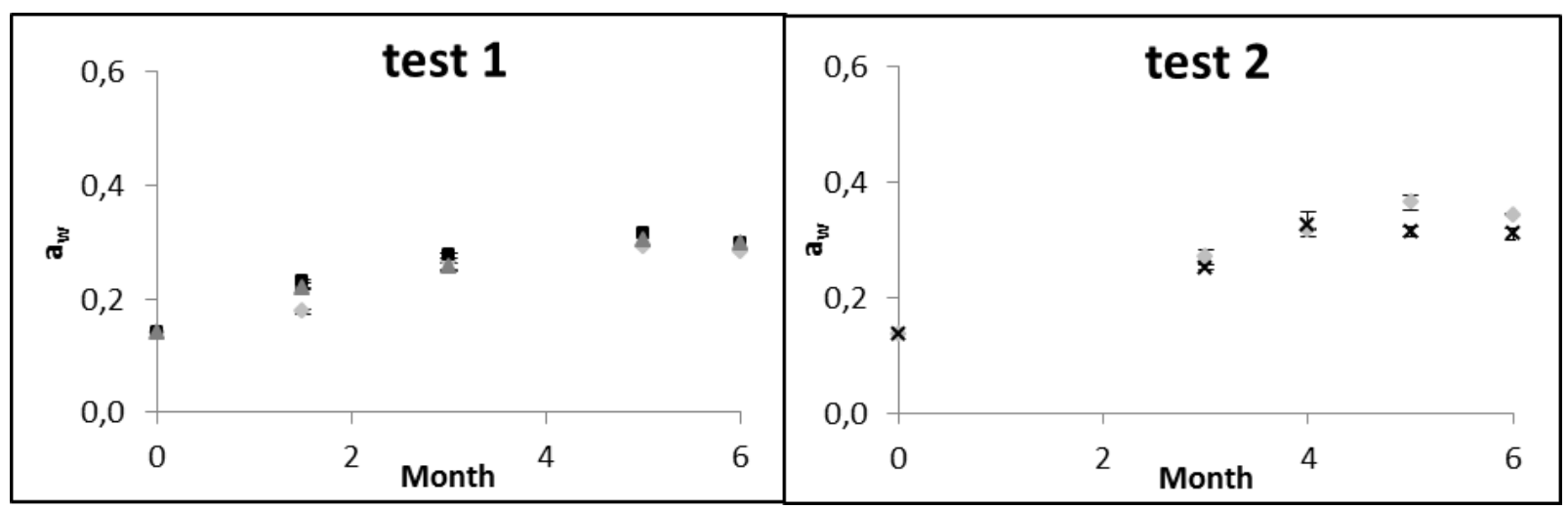

Figure 1: $a_{w}$ during the shelf life of tortilla chips packed in pouches made of Natureflex ${ }^{\top M} N 913(\mathbb{\square}), \operatorname{Natureflex}^{\top \mathrm{TM}} \mathrm{N} 931(\boldsymbol{\Delta})$, Cellophane ${ }^{T M} / M / P L A(x)$ and the reference film $(\diamond)$.

jars were left in an oven $\left(105^{\circ} \mathrm{C}\right)$ over night, then put in a dessicator for 15 minutes and weighted, the solutions were then evaporated in these jars on a hot plate until a small amount remained, which was put in the oven till dryness, cooled down in a dessicator for 15 minutes and weighted. This last procedure (oven + dessicator) was repeated until a stable weight was obtained. The overall migration in $10 \%$ and $95 \%$ ethanol was determined in triplicate, then averaged and a standard deviation was determined using Microsoft Excel.

\subsection{Statistical analysis}

For each tested parameter, measured in duplicate or triplicate, an average of the results and a standard deviation was determined using Microsoft Excel 2007.

\section{Results and discussion}

Firstly, the lab-scale experiments with tortilla chips and potato flakes, packaged in biobased packaging and reference packaging are shown and discussed. For tortilla chips, two tests separated in time have been performed as one of the biobased packages was not available during the first test. This is followed by the description of the results of industrial packaging trials with selected biobased packaging, partly based on lab-scale experiments. The main goal was to evaluate the performance of this type of packaging on large scale industrial packaging machines, and this specifically for dry biscuits and for potato flakes. Finally, results on the printability and the migration behaviour are being discussed.

\subsection{Tortilla chips}

The results of the $a_{w}$ measurements during the shelf-life of tortilla chips are shown in Figure 1 . The $\mathrm{a}_{w}$ of the tortilla chips followed an increasing trend in all the different packages during the shelf-life. Although the WVTR of both the Natureflex ${ }^{\mathrm{TM}} \mathrm{N} 913$ and the Cellophane ${ }^{\mathrm{TM}} / \mathrm{M} / \mathrm{PLA}$ film were almost twice as high as the WVTR of the Natureflex ${ }^{\mathrm{TM}} \mathrm{N} 931$ and the reference film (Table 3), no difference in $\mathrm{a}_{w}$ was detected up to 6 months of storage in both storage tests. This indicates that both the reference material and the Natureflex ${ }^{\mathrm{TM}} \mathrm{N} 913$ possess too high water barrier properties regarding the type of product to be packed. Similar results for OTR values, where packaging materials with higher OTR values compared to the reference did not have a negative effect on the quality of the packed food product, were found by Peelman et al. [6].

The peroxide values followed the same increasing trend during the shelf-life of the tortilla chips packed in the different packaging materials for both storage tests (Figure 2). MDA and FFA content remained stable at values of respectively less than $1 \mu \mathrm{mg} / \mathrm{g}$ product and around $1-2 \mathrm{~g}$ FFA/100 $\mathrm{g}$ fat for both storage tests (data not shown). Increasing PO-values indicate that lipid oxidation took place in the package during storage of tortilla chips, but the oxidation was insufficient to result in a rancid taste or flavor, as was confirmed in the sensorial evaluation. The low and stable MDA and FFA values could be explained by the fact that no secondary oxidation products were yet formed during shelf-life and that hydrolysis remained restricted. This result resembles the findings of Petukhov et al. [11], who showed that the FFA content of potato chips fried in different canola oils, did not increase above $1 \%(=\mathrm{g} / 100 \mathrm{~g})$ before the PO-value exceeded 10-15 meq $/ \mathrm{kg}$.

The $\mathrm{pH}$ values of the tortilla chips remained quite stable at values around $5.9-6.1$ in the first storage test 


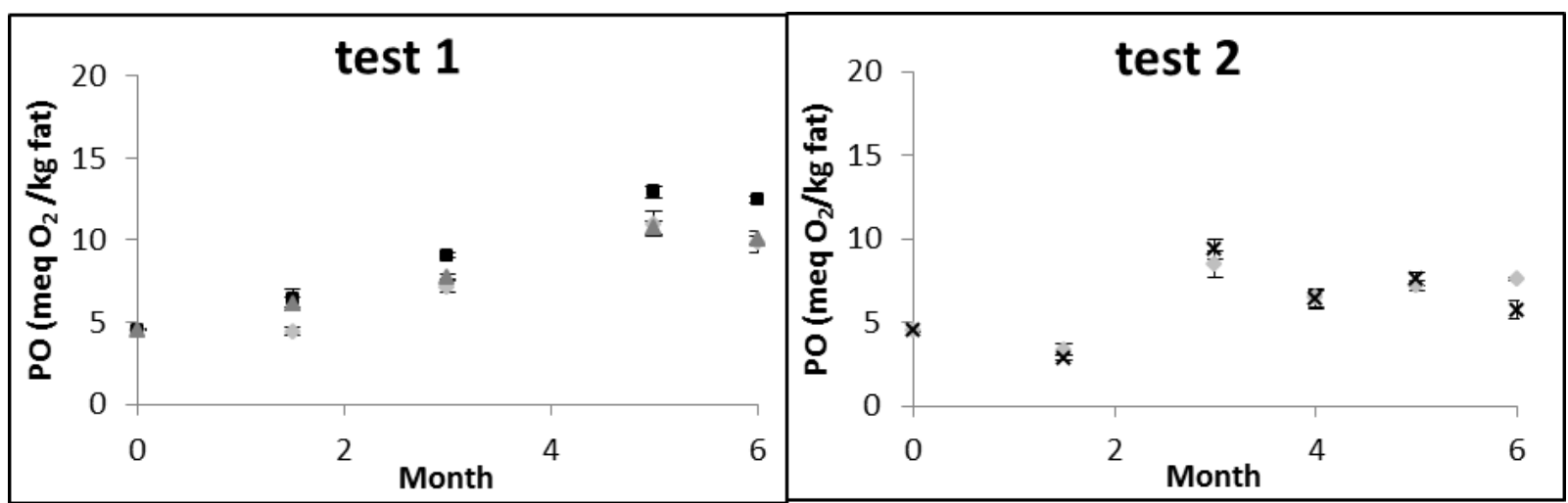

Figure 2: Peroxide value during the shelf life of tortilla chips packed in pouches made of Natureflex ${ }^{\mathrm{TM}} \mathrm{N} 913(\boldsymbol{\square}), \mathrm{Natureflex}{ }^{\mathrm{TM}} \mathrm{N} 931(\boldsymbol{\Delta})$, Cellophane $\mathrm{TM}^{\mathrm{TM}} / \mathrm{M} / \mathrm{PLA}(\mathrm{x})$ and the reference film ( $)$.

Table 4: Results of the sensory analysis + moisture content of tortilla chips (1=preferred sample, $2=$ medium preferred sample, $3=$ least preferred sample).

\begin{tabular}{|c|c|c|c|c|c|}
\hline Month & Film & Reference & Natureflex $^{\mathrm{TM}} \mathrm{N} 913$ & Natureflex ${ }^{\mathrm{TM}} \mathrm{N} 931$ & Cellophane $^{\mathrm{TM}} / \mathrm{M} / \mathrm{PLA}$ \\
\hline & & & Tortillachips test 1 & & \\
\hline \multirow[t]{3}{*}{4.5} & Moisture content (\%) & 4.51 & 4.70 & 5.15 & I \\
\hline & Preference & 3 & 1 & 2 & l \\
\hline & & & Tortillachips test 2 & & \\
\hline \multirow[t]{2}{*}{0.5} & Moisture content (\%) & 2.74 & I & / & 2.35 \\
\hline & Preference & 2 & l & l & 1 \\
\hline \multirow[t]{2}{*}{3} & Moisture content (\%) & 4.60 & l & l & 3.81 \\
\hline & Preference & 2 & l & l & 1 \\
\hline \multirow[t]{2}{*}{6} & Moisture content (\%) & 5.40 & l & l & 4.82 \\
\hline & Preference & Not crispy & l & l & Not crispy \\
\hline
\end{tabular}

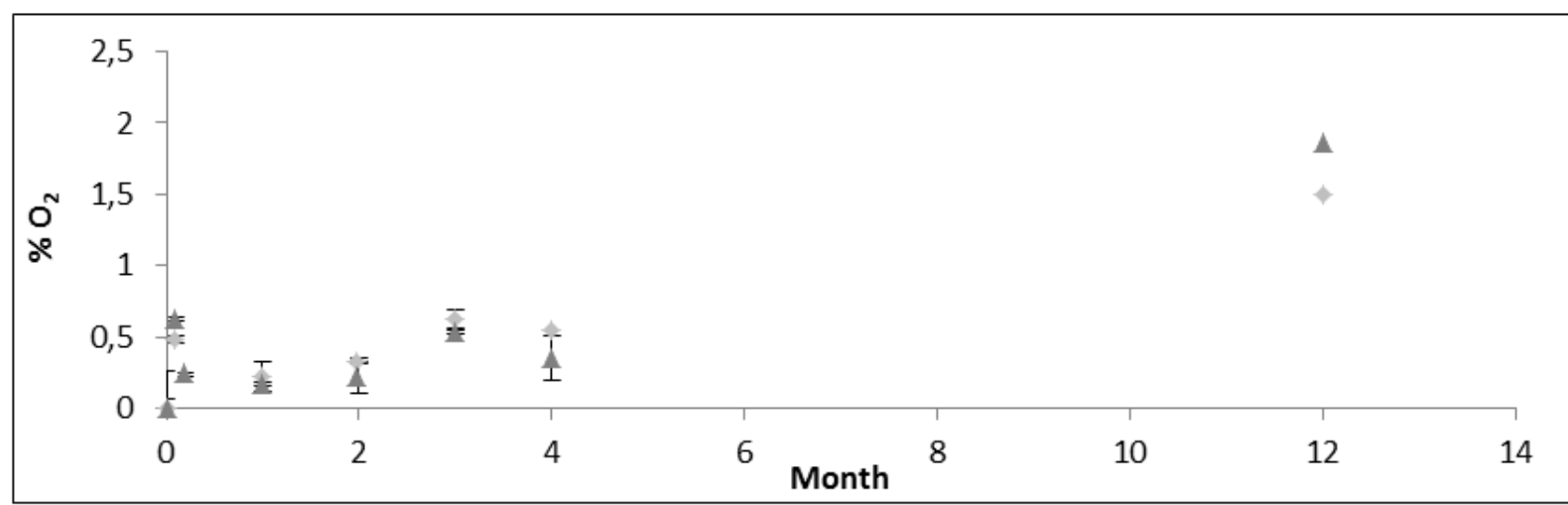

Figure 3: $\mathrm{O}_{2}$-concentration during the shelf life of potato flakes packed in Natureflex ${ }^{\mathrm{TM}} \mathrm{N} 931(\boldsymbol{\Lambda})$ and the reference film $(\diamond)$ up to month 12.

(reference - Natureflex ${ }^{\mathrm{TM}} \mathrm{N} 913-$ Natureflex $\left.{ }^{\mathrm{TM}} \mathrm{N} 931\right)$ and around $5.8-6.0$ in the second storage test (reference Cellophane $\left.\mathrm{T}^{\mathrm{TM}} / \mathrm{M} / \mathrm{PLA}\right)$ in all the different packages during the shelf-life (data not shown). This was expected, since a $\mathrm{pH}$ decrease is mostly caused by growth of microorganisms. The results of the sensory evaluation of tortilla chips is shown in Table 4. For the first storage test, it can be con- cluded that there is a preference for tortilla chips packed in the Natureflex ${ }^{\mathrm{TM}} \mathrm{N} 913$ and $\mathrm{N} 931$ films. The moisture content of the tortilla chips packed in the Natureflex ${ }^{\mathrm{TM}} \mathrm{N} 913$ and N931 films was slightly higher after 4.5 months of storage, compared to the tortilla chips packed in the reference film. This had however no influence on the sensorial appreciation of the product. For the second storage test, 
it can be concluded that there is a preference for tortilla chips packed in Cellophane $\mathrm{T}^{\mathrm{TM}} / \mathrm{M} / \mathrm{PLA}$ film up to month 3 . The moisture content of the tortilla chips packed in the Cellophane ${ }^{\mathrm{TM}} / \mathrm{M} / \mathrm{PLA}$ film was lower than that of tortilla chips packed in the reference film. At the end of shelf-life, the tortilla chips packed in both the reference packages and the biobased packages had lost their crispness, despite the fact that the maximal moisture content of $7 \%$ was not yet reached, as set by the industrial partner.

It can be concluded that the biobased packaging materials shared similar performance compared to the reference materials and that they can even have a positive influence on the sensorial appreciation.

\subsection{Potato flakes}

\subsubsection{Gas Measurements}

The evolution of the $\mathrm{O}_{2}$ concentration during shelf-life (12 month) is shown in Figure 3. Up to month 4, the $\mathrm{O}_{2}$ concentration followed the same slightly increasing trend for both packages, but at month 12, the upper limit of $1 \% \mathrm{O}_{2}$ (set by the company) was exceeded for both the biobased and the reference film. Despite the higher OTR of the biobased film compared to the reference film (Table 3), these results indicate that the Natureflex ${ }^{\mathrm{TM}} \mathrm{N} 931$ film provides a similar barrier as the reference film. No measurements could be performed between month 4 and month 12 as it was noticed after 4 months that, due to plenty of leak pouches, only enough pouches were left for one more day of analysis. This last test was thus performed after 12 months. The leaks were possibly due to particles of potato flakes ending up in the seal zone right before sealing. No results were obtained for the potato flakes packed in Skalax pouches, since the $\mathrm{O}_{2}$ concentration was already too high in all pouches at the first day of analysis. Since the oxygen permeability of the Skalax film (Table 3 ) is very similar to the one of the Natureflex ${ }^{\mathrm{TM}} \mathrm{N} 931$ film, these results were probably caused by leak pouches, due to product ending up in the seal zone and/or due to wrinkles in the seal zone because of the rather tough structure of the Skalax film. This latter resulted in difficulties to get a flat seal.

\subsubsection{Chemical parameters}

The results of $\mathrm{a}_{w}$ measurements during the shelf-life of potato flakes are shown in Figure 4. The $\mathrm{a}_{w}$ of the potato flakes was slightly increased at month 12 and was a lit- tle higher for potato flakes packed in the biobased package compared to the reference package, corresponding to the higher WVTR of the Natureflex ${ }^{\mathrm{TM}} \mathrm{N} 931$ film compared to the reference film (Table 3). Still, the higher $\mathrm{a}_{w}$-value in the biobased package ( 0.46 vs. 0.38 ) was too low to allow microbiological deterioration so therefore only the chemical changes in the lipolysis of the potato flakes were monitored throughout shelf-life.

MDA values remained stable at values less than $1 \mu \mathrm{mg} / \mathrm{g}$ product (data not shown). Low MDA in dry products can be caused by MDA being in the 'volatile chelated' form due to the low water content [12, 13]. Up to month 12 , the hexanal content in both the biobased film and the reference film followed a similar increasing trend (Fig. 5). This means oxidation of the packed product took place during storage. The odor threshold value of $479 \mathrm{ppb}$ in deionized water [14] or $320 \mathrm{ppb}$ in paraffin oil [15] was not reached after 12 months. Also Boggs et al. [16] found only clear flavor deterioration of potato granules when values of $2500 \mathrm{ppb}$ were reached. So although no sensorial evaluation was performed at month 12 , it seems reasonable to assume that the level of hexanal as a marker for secondary oxidation products was too low to result in a rancid taste or off-flavor.

The $\mathrm{pH}$ values of the potato flakes remained quite stable at values around 5.9-6.0 in all the different packages during the shelf-life (data not shown). This was expected, since a $\mathrm{pH}$ decrease is mostly caused by growth of microorganisms. The sensorial analysis showed no difference in reconstitution between the potato flakes packed in the Natureflex ${ }^{\mathrm{TM}} \mathrm{N} 931$ film and in the reference film after 1 month.

It could be concluded that, despite the higher OTR and WVTR values, the Natureflex ${ }^{\mathrm{TM}} \mathrm{N} 931$ film performs similarly as the reference material and can guarantee the quality of the food product during shelf-life. This corresponds to the findings of Peelman et al. [6], who found that slightly higher OTR values and/or slightly higher oxygen concentrations in the headspace of the biobased packages did not cause a faster deterioration of the food product and to the findings of Romani et al. [17], who concluded that dry biscuits packed in PLA based films underwent a maximum hydration without adversely affecting other quality parameters.

\subsection{Performance in industrial environment}

Since the laboratory scale storage tests demonstrated the potential of biobased materials to guarantee the quality of long shelf-life food products, tests were also performed at 


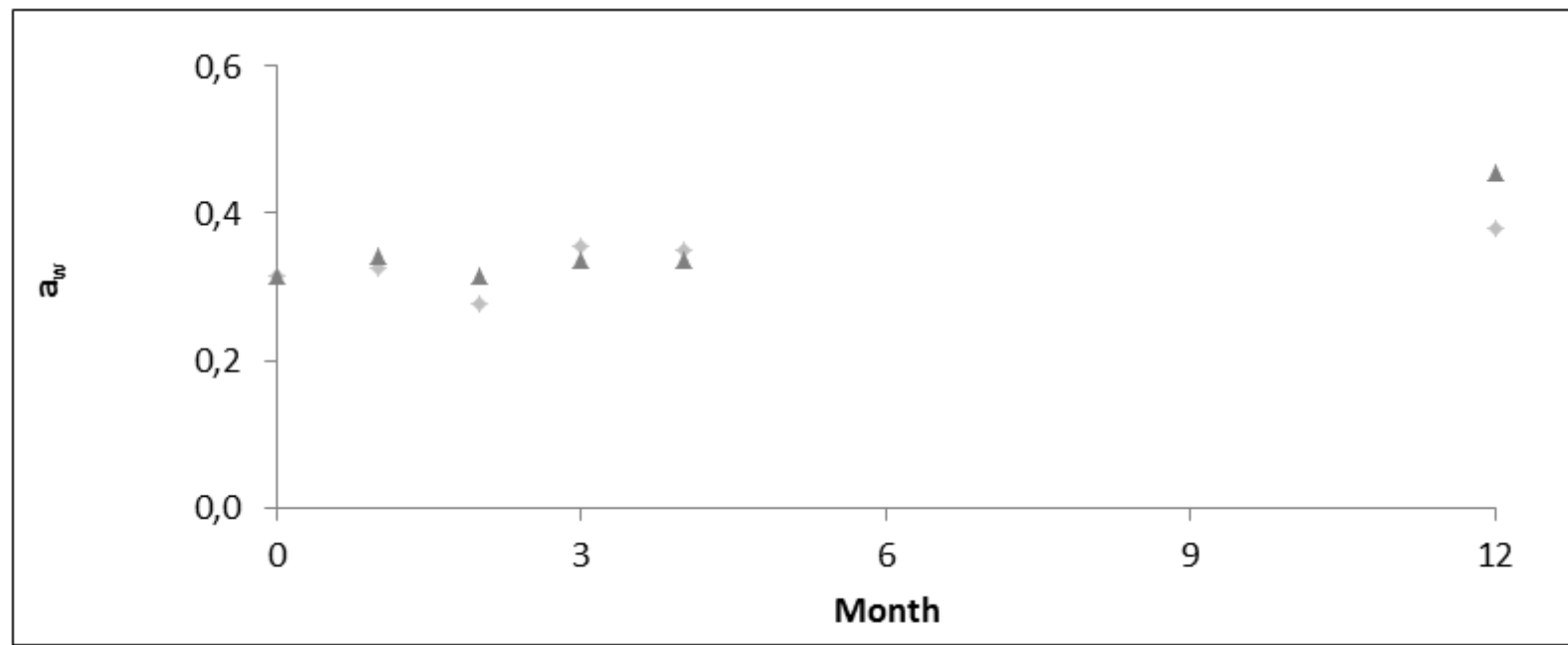

Figure 4: $a_{w}$ during the shelf life of potato flakes packed in pouches made of Natureflex ${ }^{T M} N 931(\boldsymbol{\Lambda})$ and the reference film ( () ).

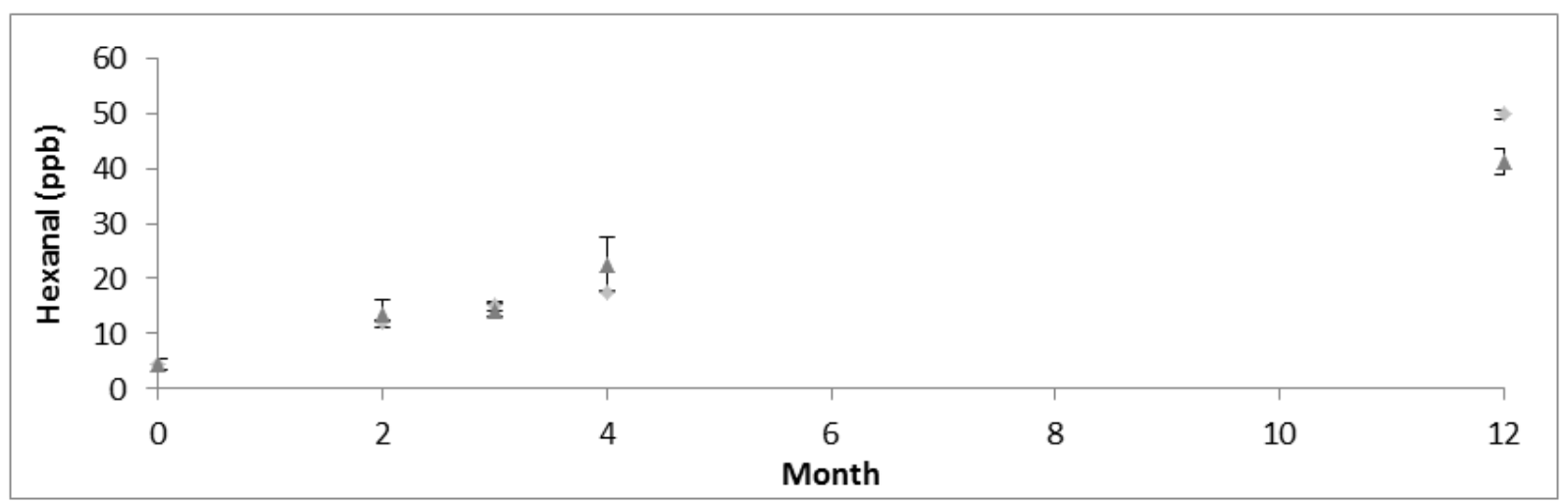

Figure 5: Hexanal content during the shelf life (up to month 12) of potato flakes packed in Natureflex ${ }^{\mathrm{TM}} \mathrm{N} 931(\boldsymbol{\Delta})$ and the reference film ( $($) ).

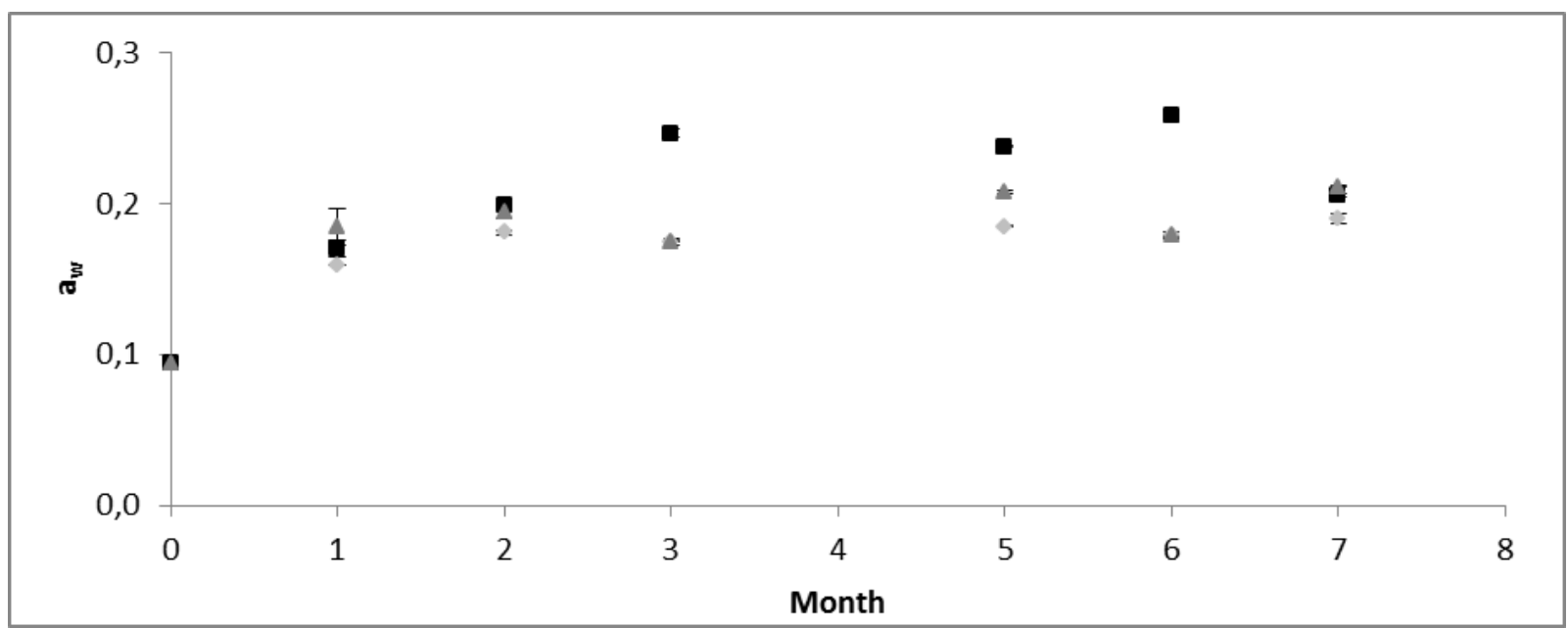

Figure 6: $\mathrm{a}_{w}$ during the shelf life of dry biscuits packed in individual pouches made of Natureflex ${ }^{\mathrm{TM}} \mathrm{N} 948(\boldsymbol{\square}), \mathrm{Natureflex}^{\mathrm{TM}} \mathrm{NK}(\boldsymbol{\Delta})$ and the reference film ( $\downarrow$ ) packed in the conventional bundle pack.

industrial scale. Therefore, several films were selected to pack food products on industrial packaging lines.
For potato flakes, Skalax (Xylophane), Natureflex ${ }^{\mathrm{TM}} \mathrm{N} 913$ and N931 and Cellophane ${ }^{\mathrm{TM}} / \mathrm{M} / \mathrm{PLA}$ were selected. The 
Table 5: $\mathrm{O}_{2}$-concentration in the biobased pouches containing potato flakes after 6 weeks of storage (case study at the company).

\begin{tabular}{|c|c|c|}
\hline Film & $\% \mathbf{O}_{2}^{a, c}$ & $\% \mathbf{0}_{2}^{b, c}$ \\
\hline Skalax & $>20->20$ & $>20-/$ \\
\hline Natureflex ${ }^{\mathrm{TM}} \mathrm{N} 913$ & $1.5-8.9$ & $11.8-20.8$ \\
\hline Natureflex ${ }^{T M}$ N931 & $20.7-/$ & $7.3-19.0$ \\
\hline Cellophane $^{T M} / \mathrm{M} / \mathrm{PLA}$ & $1.0-1.0$ & $19.2-20.9$ \\
\hline
\end{tabular}

${ }^{a}$ Pouch on top, ${ }^{b}$ Pouch at bottom of box

${ }^{c}$ Results of 2 measurements ( 2 different bags)

tested Skalax film had a new formulation with a lower barrier compared to the Skalax film that was used in the previously demonstrated storage tests. All four films ran smoothly over the machine (vertical flow pack) and resulted in good sealed pouches. The longitudinal seals were made at $160^{\circ} \mathrm{C}, 140^{\circ} \mathrm{C}, 135^{\circ} \mathrm{C}$ and $135^{\circ} \mathrm{C}$ for respectively the Skalax, Natureflex ${ }^{\mathrm{TM}} \mathrm{N} 913$, Natureflex ${ }^{\mathrm{TM}} \mathrm{N} 931$ and Cellophane $\mathrm{T}^{\mathrm{TM}} / \mathrm{M} / \mathrm{PLA}$ film. The horizontal seals were made at $130^{\circ} \mathrm{C}, 130^{\circ} \mathrm{C}, 125^{\circ} \mathrm{C}$ and $120^{\circ} \mathrm{C}$ for respectively the Skalax, Natureflex ${ }^{\mathrm{TM}} \mathrm{N} 913$, Natureflex ${ }^{\mathrm{TM}} \mathrm{N} 931$ and Cellophane $^{\mathrm{TM}} / \mathrm{M} / \mathrm{PLA}$ film. For all films, pouches were filled with $5 \mathrm{~kg}$ of potato flakes and MAP packed (100\% $\mathrm{N}_{2}$ ). The pouches were packed per two in a box (one pouch on the bottom, one pouch on top). The $\mathrm{O}_{2}$-concentration in these pouches was measured after six weeks (Table 5). The results show that only the Cellophane $\mathrm{TM}^{\mathrm{TM}} / \mathrm{M} / \mathrm{PLA}$ pouches that were on top in the box, still had an acceptable oxygen concentration $(<1 \%)$, but this concentration was higher than the concentration in the reference package $(<0,25 \%$ during 7 months). Furthermore, since the biobased films have a good oxygen barrier (Table 3) and mostly a clear difference between top and bottom storage of the pouches was observed, these results probably mean the barrier properties of the film are sufficient (as was also showed by the storage test with Natureflex ${ }^{\mathrm{TM}} \mathrm{N} 931$, see 3.2), but the films are too brittle to contain larger contents and microleaks are formed because of the handling and storage conditions (sensitive to pressure (e.g. effect overlying bag)).

For dry biscuits, the Natureflex ${ }^{\mathrm{TM}} \mathrm{N} 948$ (home compostable and new version of N913), the Natureflex ${ }^{\mathrm{TM}} \mathrm{NK}$ (cellulose-based film without starch coating and good moisture barrier) and the Cellophane $\mathrm{T}^{\mathrm{TM}} / \mathrm{M} / \mathrm{PLA}$ films were selected, because these films had a high water barrier; a very important parameter for dry biscuits. Furthermore, these types of packaging materials were compatible with flow pack applications. The Natureflex ${ }^{\mathrm{TM}} \mathrm{N} 948$ film ran smoothly over the machine (horizontal flow pack) and a good sealed package could be made (longitudinal seal: $150^{\circ} \mathrm{C}$ - vertical seal: $180^{\circ} \mathrm{C}$ ), but the film was too thick, causing the formation of little holes at the intersect of the longitudinal and vertical seal. The Natureflex ${ }^{\mathrm{TM}} \mathrm{NK}$ film also ran smoothly over the machine and good sealed packages could be made (longitudinal seal: $175^{\circ} \mathrm{C}$ - vertical seal: $165^{\circ} \mathrm{C}$ ). From the Cellophane ${ }^{\mathrm{TM}} / \mathrm{M} /$ PLA film no good sealed pouches could be made on the machine. So no results were obtained for this test.

Following up of the individual packed biscuits without bundle pack was only performed at the company $\left(25^{\circ} \mathrm{C}\right.$ $-60 \% \mathrm{RH}$ ) and they decided to stop the test after 1 month, since the results were insufficient (too much water uptake). The moisture uptake of biscuits which were individually packed in the Natureflex ${ }^{\mathrm{TM}} \mathrm{N} 948$ was already at a maximum after 14 days (+ $6 \%$ moisture uptake) and an offflavor was detected. The moisture uptake of biscuits which were individually packed in the Natureflex ${ }^{\mathrm{TM}} \mathrm{NK}$ was too high after 1 month (+ 4\% moisture uptake), compared to biscuits individually packed in the reference films $(+2 \%$ moisture uptake). The higher moisture uptake of biscuits packed in the biobased films can be explained by their higher WVTR compared to the reference film (Table 3). This is a clear difference with the results of the tortilla chips, where the higher WVTR had no negative influence on the quality of the food product. The performance of biobased packaging materials is very food product dependent. It might also be stated that the tortilla chips are slightly overpacked, so the use of a lower barrier material does not affect the quality, while this is not the case for dry biscuits, where a slightly lower barrier immediately has a clear influence on the quality of the food product.

When individually packed biscuits (Natureflex ${ }^{\mathrm{TM}} \mathrm{N} 948$ - Natureflex ${ }^{\mathrm{TM}} \mathrm{NK}$ - reference) were packed in a conventional bundle pack, no difference was noticed between biscuits packed in the Natureflex ${ }^{\mathrm{TM}} \mathrm{NK}$ film or biscuits packed in the reference film after 1 month, but a big difference was noticed between biscuits packed in the Natureflex ${ }^{\mathrm{TM}} \mathrm{N} 948$ film and biscuits packed in the reference film. This difference was noticed by company experts based on the one hand on sensorial evaluation and on the other hand on moisture uptake, which exceeded the limit of $3 \%$ as set by the industrial partner. Therefore, the company decided to stop the test after 1 month.

At Ghent University, $\mathrm{a}_{w}$ of the individually packed biscuits, packed in a conventional bundle pack was followed up until the end of shelf-life. The results of the $a_{w}$ during the shelf-life of these dry biscuits is shown in Figure 6 . The $\mathrm{a}_{w}$ of the dry biscuits followed an increasing trend in all the different packages during the shelf-life, but higher values were observed in the Natureflex ${ }^{\mathrm{TM}} \mathrm{N} 948$ film compared to the Natureflex ${ }^{\mathrm{TM}} \mathrm{NK}$ and reference film. 
Since the WVTR of both the Natureflex ${ }^{\mathrm{TM}} \mathrm{NK}$ and the Natureflex ${ }^{\mathrm{TM}} \mathrm{N} 948$ film is similar according to the technical datasheet and the information of the supplier (Table 3), the difference can probably be explained by the thickness of the Natureflex ${ }^{\mathrm{TM}} \mathrm{N} 948 \mathrm{film}(55 \mu \mathrm{mm})$, which was greater than the thickness of the Natureflex ${ }^{\mathrm{TM}} \mathrm{NK}(30 \mu \mathrm{mm})$ and the reference film $(26 \mu \mathrm{m})$. Because the film was thicker, the pressure on the sealing zone was too high, causing the formation of micro leaks, which could be visually observed.

It can be concluded that the effect of the higher WVTR values of both biobased films compared to the reference film (Table 3), was not observed during the $\mathrm{a}_{w}$ monitoring at Ghent University or during the test in the bundle pack at the company, but the effect was observed in the test with the individual packages at the company. This means the crispness of individual packed dry biscuits could only be guaranteed throughout the shelf-life as long as the individually packed biscuits remained packed in the bundle pack. But once this bundle pack was opened, the moisture uptake of dry biscuits packed in the biobased packages was too high to guarantee the quality during the rest of the shelf-life.

\subsection{Printability tests}

The printing of the Natureflex ${ }^{\mathrm{TM}} \mathrm{N} 913$ film in different colors gave no problems and the film is now commercially used as rice and pasta packaging.

Printing of the multilayer PLA also gave no problems and the scratch test, tape test, tensile test and adhesion tape test showed that no adhesion problems occurred while scratching, elongating or stretching the film. This means a perfect adhesion from the printed inks onto the foil. When a higher volume of ink was applied on the surface, a better adhesion of the ink was obtained.

The residual solvent content analysis showed that the total concentration in several samples was above $20 \mathrm{mg} / \mathrm{m}^{2}$, indicating that the PLA film is very receptive to solvents. This could lead to odor and flavor defects in food products. Furthermore, retarders (1-etoxy-2-propanol and 1-propoxy-2-propanol) were already present in the inks. These retarders are only necessary for detailed printing (e.g. fine dots), so it could be agreed with the supplier to leave them out when no printing in detail is needed. If these retarders are left out, the total concentration of residual solvents will be much lower. Furthermore, the determination of the dry weight showed that the total residual amount of both single components (cyan or magenta) exceeded the maximum of 0.5\% (EN 13432 Packaging). The overlap sample (cyan and magenta) was in accordance with the standard (5\%). It is noticed that the limit is much more stringent for single components than for overlap samples (respectively $0.5 \%$ and $5 \%$ ). These tests showed that the choice of ink (e.g. with or without retarders) and the print design are very important when printing PLA films. The amount of ink remaining on the surface and the amount of residual solvents should not be too high in order to avoid negative effects on the packed food product (by migration).

It can be concluded that cellulose-based and PLAbased surfaces can be easily printed, but for PLA surfaces, the choice of ink and print design is important.

\subsection{Overall migration}

Since interference with the blank sample (film stored at the same conditions as the other samples, but not in contact with olive oil) was observed in the tests with the Natureflex ${ }^{\mathrm{TM}} \mathrm{N} 913$ and $\mathrm{N} 931$ in contact with olive oil, probably caused by fatty acids present in the starch coating, it was decided to use an alternative food simulant (95\% ethanol). The problems encountered during the migration tests with olive oil as a food simulant showed that the test procedures set in current legislation regarding plastic materials and articles intended to come into contact with food [10] might not be suited for all new biobased materials. The results of the overall migration tests in $10 \%$ and 95\% ethanol are shown in Table 6.

Table 6: Overall migration of biobased materials ( 10 days $\left.-40^{\circ} \mathrm{C}\right)$.

\begin{tabular}{|c|c|c|}
\hline \multirow[t]{2}{*}{ Film } & \multicolumn{2}{|c|}{ Overall migration $\left(\mathrm{mg} / \mathrm{dm}^{2}\right)$} \\
\hline & $\begin{array}{c}10 \% \\
\text { ethanol }^{a}\end{array}$ & $\begin{array}{c}95 \% \\
\text { ethanol }^{a}\end{array}$ \\
\hline Natureflex ${ }^{\mathrm{TM}}$ N913 & $1.1 \pm 0.2$ & $4.0 \pm 0.7$ \\
\hline Natureflex ${ }^{\mathrm{TM}}$ N931 & $1.4 \pm 0.2$ & $4.5 \pm 0.4$ \\
\hline Natureflex ${ }^{\mathrm{TM}}$ N913/PLA & $2.8 \pm 0.2$ & $8.0 \pm 0.2$ \\
\hline Cellophane $^{T M} / M / P L A$ & $4.0 \pm 1.1$ & $6.5 \pm 0.4$ \\
\hline Natureflex ${ }^{T M}$ NK & $2.9 \pm 0.3$ & $1.0 \pm 0.2$ \\
\hline $\begin{array}{l}\text { Multilayer PLA }- \text { not } \\
\text { printed }\end{array}$ & $0.9 \pm 0.4$ & $<0.0 \pm 0.1$ \\
\hline Multilayer PLA - printed & $0.2 \pm 0.2$ & $<0.0 \pm 0.1$ \\
\hline PLA tray & $0.9 \pm 0.2$ & $2.2 \pm 1.6$ \\
\hline
\end{tabular}

The limit of $10 \mathrm{mg} / \mathrm{dm}^{2}$ was never exceeded for the tests in 10\% and 95\% ethanol. This means all tested materials are in correspondence with the specifications laid 
down in the legislation [10] for use as a packaging materials for all types of food products, except acidic food products, for any long term storage at room temperature of below. Although the cellulose-based films (Natureflex ${ }^{\mathrm{TM}}$ ) have to comply with Commission Directive 2007/42/EC [19], it is stated in this legislation that these films should also comply with the overall migration limits. Furthermore, it can be stated that more migration was observed in $95 \%$ ethanol compared to $10 \%$ ethanol, except for the Natureflex ${ }^{\mathrm{TM}} \mathrm{NK}$ and the multilayer PLA films. This suggests that especially compounds with a lipophilic character (e.g. vegetable oils used in the coatings) migrated from the biobased films. From Natureflex ${ }^{\mathrm{TM}} \mathrm{NK}$ and the multilayer PLA films especially compounds with a hydrophilic character migrated.

\section{Conclusions}

Biobased materials have potential for long shelf-life food applications, including MAP packaging. It was demonstrated that the quality and crispness of several long shelflife food products could be guaranteed when packed in biobased multilayer materials, even when materials with lower moisture barrier were used. Furthermore, migration tests showed that the films can be used as a food contact material and it was demonstrated that the films can be printed. Still, it was noticed for specific food products that there is a need for a film with a very high moisture barrier. This can be tackled by adjusting the thickness of the material as well as applying coating techniques or other barrier technologies to reach very high moisture barriers. It should also be mentioned that the brittleness of some films, the seal properties (time, temperature, pressure), which may require different machine settings and the price currently hinder a general shift towards the use of these biobased packaging materials. However, from a technical point of view, these materials show promising results for long shelf-life food products.

Acknowledgement: These results were obtained in the framework of a collective research (CO 095062) supported by the Institute for the Promotion of Innovation by Science and Technology in Flanders, Belgium (IWT) and by 22 participating companies in close collaboration with 5 research institutes (Ghent University, University College of Ghent, Packaging Centre, Belgian Packaging Institute and the Flemish Plastic Centre).

\section{References}

[1] Arvanitoyannis I.S., Totally and partially biodegradable polymer blends based on natural synthetic macromolecules: preparation, physical properties, and potential as food packaging materials, J. Macromol. Sci. R. M. C., 1999, 39, 205-271

[2] Robertson G.L., Food Packaging. Principles and Practice. Taylor \& Francis, Boca Raton, 2006

[3] Siracusa V., Rocculi P., Romani S., Dalla Rosa M., Biodegradable polymers for food packaging, Trends Food Sci. Tech., 2008, 19, 634-643

[4] European Bioplastics, http://en.european-bioplastics.org/, last accessed: 15/05/2013.

[5] Highlights in bioplastics, http://www.biodeg.net/fichiers/High lights\%20in\%20Bioplastics\%20(Eng).pdf, last accessed: $24 /$ $05 / 2013$

[6] Peelman N., Ragaert P., Vandemoortele A., Verguldt E., De Meulenaer B., Devlieghere F., Use of biobased materials for modified atmosphere packaging of short and medium shelf-life food products. Innov. Food Sci. Emer., 2014, 26, 319-329

[7] Papastergiadis A., Mubiru E., Van Langenhove H., De Meulenaer B., Malondialdehyde Measurement in Oxidized Foods: Evaluation of the Spectrophotometric Thiobarbituric Acid Reactive Substances (TBARS) Test in Various Foods. J. Agr. Food Chem., 2012, 60, 9589-9594

[8] Gray J.I., Measurement of lipid oxidation: A review., J. Am. Oil Chem. Soc., 1978, 55, 539-546

[9] Robards K., Kerr A.F., Patsalides E., Rancidity and its Measurement in Edible Oils and Snack Foods : A Review, Analyst, 1988, $113,213-224$

[10] EC 10/2011, Commission Regulation (EU) No 10/2011 of 14 January 2011 on plastic materials and articles intended to come into contact with food

[11] Petukhov I., Malcolmson L.J., Przybylski R., Armstrong L., Storage Stability of Potato Chips Fried in Genetically Modified Canola Oils, J. Am. Oil Chem. Soc., 1999, 76, 889-896

[12] Kwon T., Watts B.M., Malonaldehyde in aqueous solution and its role as a measure of lipid oxidation., J. Food Sci., 1964, 29, 294-302

[13] Ventanas S, Estevez M, Tejeda J.F, Riuz J., Protein and lipid oxidation in Longissimus dorsi and dry cured loin from Iberian pigs as affected by crossbreeding and diet, Meat Sci., 2006, 72, 47655

[14] Tandon K.S, Baldwin E.A, Shewfelt R.L., Aroma perception of individual volatile compounds in fresh tomatoes (Lycopersicon esculentum, Mill.) as affected by the medium evaluation, Postharvest Biol. Tec., 2000, 20, 261-268

[15] Meijboom P.W., Relationship between molecular structure and flavour perceptibility of aliphatic aldehydes, J. Am. Oil Chem. Soc., 1964, 41, 326-328

[16] Boggs M., Buttery R., Venstrom D., Belote M., Relation of Hexanal in Vapor Above Stored Potato Granules to Subjective Flavor Estimates, J. Food Sci., 1964, 29, 487-489

[17] Romani S., Tappi S., Balestra F., Rodriquez Estrada M.T., Siracusa V., Rocculi P., Dalla Rosa M., Effect of different new packaging materials on biscuit quality during accelerated storage. J. Sci. Food Agr., 2015, 95, 1736-1746

[18] Peelman, N., Ragaert, P., De Meulenaer, B., Adons, D., Peeters, R., Cardon, L., Van Impe, F., Devlieghere, F., Application of bio- 
plastics for food packaging, Trends Food Sci. Tech., 2013, 32, 128-141
[19] Commission Directive 2007/42/EC of 29 June 2007 relating to materials and articles made of regenerated cellulose film intended to come into contact with foodstuffs 